\title{
HIDUP KONTEMPLATIF DEWASA INI: Mendalami Butir-butir Konstitusi Apostolik Paus Fransiskus VULTUM DEI QUAERERE
}

\author{
Sihol Situmorang*
}

\begin{abstract}
Abstrak
Pemeluk hidup kontemplatif merupakan kelompok kecil dari kawanan umat Allah. Namun, keberadaan mereka sangat penting, ibarat detak jantung iman dan cinta Gereja kepada Allah dan manusia. Selaku gembala yang penuh perhatian atas hidup kawanannya, Paus Fransiskus memutuskan mempromulgasikan Konstitusi Apostolik Vultum Dei Quaerere bagi para suster kontemplatif. Seraya bersyukur atas kehadiran pemangku hidup kontemplatif dalam Gereja, Paus mengajak para suster kontemplatif mencermati sejumlah nilai dan topik penting, supaya panggilan hidup istimewa ini semakin berbuah melimpah.
\end{abstract}

Kata-kata Kunci: Kontemplatif, Gereja, hidup bakti, formasi, doa, sabda Allah, Paus Fransiskus, persaudaraan, askese, norma yuridis.

\section{Pengantar}

Setelah menetapkan tahun 2015 sebagai Tahun Hidup Bakti, Jumat, 22 Juli 2016, Vatikan merilis Konstitusi Apostolik Vultum Dei Quaerere (Mencari Wajah Allah), tentang Hidup Kontemplatif Perempuan. Konstitusi Apostolik ini terbit 66 tahun setelah Konstitusi Sponsa Christi Paus Pius XII. Dokumen ini dilatarbelakangi berkurangnya jumlah komunitas hidup kontemplatif di Eropa dan Amerika yang semakin menua dan upaya penanaman hidup kontemplatif dalam Gereja-gereja muda di Afrika, Asia dan Amerika Latin. Perubahan pesat dalam lima dekade sejak Konsili Vatikan II turut melatarbelakangi terbitnya dokumen ini. ${ }^{1}$ Paus Fransiskus menekankan

1 Ricardo Benotti, "Vultum Dei quaerere", Pope Francis on women's contemplative life: "the world needs you." Prudence with media communications and candidates' recruitment, dalam https://agensir.it/chiesa/2016/07/23/vultumdei-quaerere-pope-francis-on-womens-contemplative-life-the-world-needs-youprudence-with-media-communications-and-candidates-recruitment/; Holy See 
pentingnya menggulirkan dialog dengan masyarakat seraya menjaga nilai-nilai fundamental hidup kontemplatif, seperti keheningan, mendengar dengan penuh perhatian, panggilan kepada hidup batin, dll. Paus berharap bahwa hidup kontemplatif dapat dan mesti bisa memberi warna baru terhadap pola pikir yang berkembang dewasa ini. ${ }^{2}$

Konstitusi ini terdiri dari dua bagian. Pertama, bagian doktrinal yang menggaris bawahi inti hidup tarekat kontemplatif kaum perempuan. Kedua, bagian norma-norma yuridis. Di antara kedua bagian ini terdapat dua belas topik yang perlu dicermati lebih dalam agar hidup kontemplatif semakin lebih berbuah. ${ }^{3}$

Konstitusi Apostolik ini ditujukan bagi biara-biara kontemplatif perempuan, baik yang seutuhnya kontemplatif maupun tidak, federasi atau tidak, yang anggotanya lebih dari 43.000 suster tersebar di seluruh dunia. Dalam Konstitusi ini, istilah hidup kontemplatif dan hidup monastik digunakan dalam pengertian yang sama. ${ }^{4}$

\section{Pentingya Hidup Kontemplatif ${ }^{5}$}

Paus Fransiskus berharap agar penyandang hidup bakti mencermati zaman ini dengan bijaksana. Seraya menyatakan penghargaan, pujian dan terima kasih Gereja kepada suster kontemplatif, Paus mengingatkan bahwa Gereja tetap membutuhkan mereka untuk menuntun manusia menuju kabar gembira Injil. Di tengah

Press Office, Summary of the Apostolic Constitution Vultum Dei quaerere, 22.07.2016,

dalam https://press.vatican.va/content/salastampa/en/bollettino/pubblico/2016/07 /22/160722c.html; Scholastika Häring, Seeking the Face of God, a Commentary on the Apostolic Constitution Vultum Dei Quaerere: Contemplative Life in Religious Orders of Women, by Pope Francis, dalam http://www.aimintl.org/en/2015-0529-13-29-49/bulletin-112/vultum-dei-quaerere

2 Vatican Radio, Apostolic Constitution, Vultum Dei quaerere (Seeking the Face of God), On Women's Contemplative Life, dalam https://www.cssr.news/2016/07/apostolic-constitution-vultum-dei-quaerereseeking-the-face-of-god-on-womens-contemplative-life/; Ricardo Benotti, "Vultum Dei quaerere", ...

${ }^{3}$ Scholastika Häring, Seeking the Face of God, ,...

${ }^{4}$ Scholastika Häring, Seeking the Face of God, ...

${ }^{5}$ Vultum Dei Quaerere (selanjutnya disingkat VDQ), no. 5-6. 
dunia yang dikuasai oleh pola pikir yang mementingkan kuasa, kekayaan dan kenikmatan, misi ini jelas tidaklah mudah. Para suster kontemplatif diharapkan tampil sebagai rambu dan obor bagi perjalanan manusia; penjaga pagi yang menunjukkan Kristus -jalan, kebenaran dan hidup- kepada dunia. Sebagai karunia yang tak ternilai dan tak tergantikan, hidup bakti merupakan anugerah cinta yang penuh gairah kepada Tuhan dan manusia tedorong oleh niat yang bernyala-nyala untuk melihat wajah Allah. Cara pandang hidup bakti yang melihat segala sesuatu dari sudut iman memungkinkan manusia melihat dunia dan sesama dengan cara melihat Allah sendiri. Paus Fransiskus menghimbau supaya para suster kontemplatif tetap gigih bertahan menghadapi timbulnya godaan kelesuan, rutinitas dan kurangnya entusiasme. 6

\section{Dua Belas Tema Refleksi dan Discerment}

Dalam Konstitusi Apostolik ini, Paus menekankan perlunya mengadakan refleksi dan discerment seputar dua belas aspek dalam hidup bakti secara umum dan secara khusus dalam tradisi monastik untuk menemukan tujuan panggilan khusus mereka.

\section{Formasi ${ }^{7}$}

Formasi merupakan suatu proses menuju konfigurasi dengan Tuhan Yesus. Formasi merupakan perjalanan yang tak pernah selesai dan menuntut pertobatan terus-menerus. Paus mendesak biara-biara untuk memberi perhatian khusus penerapan discerment atas panggilan dan hidup rohani, dan tidak tergoda untuk terutama memikirkan jumlah anggota. Lebih jauh, Paus mengingatkan bahwa formasi membutuhkan waktu yang luas, antara sembilan sampai dua belas tahun. ${ }^{8}$

${ }^{6}$ Vatican Radio, Apostolic Constitution, Vultum Dei quaerere; Holy See Press Office, Summary of the Apostolic Constitution Vultum Dei quaerere, ...

$7 V D Q$, no. 13-15.

8 Vatican Radio, Apostolic Constitution, Vultum Dei quaerere, ...; Holy See Press Office, Summary of the Apostolic Constitution Vultum Dei quaerere,...; Ricardo Benotti, "Vultum Dei quaerere", ...; Scholastika Häring, Seeking the Face of God, ... 


\section{$\operatorname{Doa}^{9}$}

Doa merupakan inti hidup bakti. Dengan doa, penyandang hidup bakti membuka hati untuk merangkul manusia, khususnya mereka yang menderita, seperti tawanan, imigran, pengungsi, korban kekerasan, keluarga yang mengalami kesulitan, pengangguran, orang miskin dan sakit. Paus mendesak para suster kontemplatif agar menyampaikan doadoa permohonan atas nama semua orang. Dengan demikian komunitas kontemplatif menjadi sekolah doa sejati. ${ }^{10}$

\section{Sabda Allah ${ }^{11}$}

Paus Fransiskus menekankan posisi sentral Sabda Allah dalam hidup religius. Sabda Allah adalah sumber utama dan pertama spiritualitas dan dasar kesatuan komunitas. Hal itu tampak melalui lectio divina, yang menolong pembaca bergerak dari teks Kitab Suci kepada hidup. Lectio divina menolong kita menjembatani jurang antara spiritualitas dan hidup harian, dan menuntun kita dari mendengar kepada mengetahui, dan dari pengetahuan kepada cinta. Paus meminta agar seluruh hari, baik pribadi maupun komunitas, ditata sekeliling Sabda Allah, supaya melalui intuisi (gerak hati), para suster kontemplatif ditolong melihat kehendak Allah. Paus menegaskan, lectio divina mesti bermuara pada actio, yang menggerakkan orang beriman untuk menjadikan hidupnya suatu pemberian bagi orang lain dalam cinta kasih. ${ }^{12}$

\section{Sakramen Ekaristi dan Rekonsiliasi ${ }^{13}$}

Paus Fransiskus menggarisbawahi pentingnya sakramen Ekaristi dan Rekonsiliasi. Paus menganjurkan untuk memperpanjang perayaan Misa melalui adorasi Ekaristi dan penerimaan Pengampunan, sebagai

${ }^{9} V D Q$, no. 16-18.

${ }^{10}$ Holy See Press Office, Summary of the Apostolic Constitution Vultum Dei quaerere, ...; Ricardo Benotti, "Vultum Dei quaerere", ...; Scholastika Häring, Seeking the Face of God, ...

${ }^{11} V D Q$, no. 19-21.

12 Holy See Press Office, Summary of the Apostolic Constitution Vultum Dei quaerere; José Rodriguez Carball, Prayer With No Bounds.

$13 V D Q$, no. 22-23. 
sarana khusus mengkontemplasikan wajah belas kasih Bapa. Dengan mengalami pengampunan Allah, seseorang menerima rahmat menjadi nabi dan pelayan belas kasih Allah serta menjadi sarana rekonsiliasi dan damai yang sangat dibutuhkan oleh dunia. ${ }^{14}$

\section{Persaudaraan $^{15}$}

Hidup bersaudara dalam komunitas adalah refleksi atas cara berada dan pemberian diri Allah dan bentuk pertama karya evangelisasi. Paus menekankan perlunya hidup komunitas bertumbuh menuju suatu persekutuan fraternal yang otentik. Keberadaan sebuah komunitas tergantung dari kontribusi setiap anggota melalui sense of belonging. Di tengah masyarakat yang ditandai pengkotak-kotakan dan kesenjangan kelas, pemeluk hidup bakti menunjukkan bahwa hidup bersama dan saling melengkapi tidak mustahil, kendati terdapat perbedaan usia, pendidikan dan budaya. Perbedaan bukanlah rintangan untuk menjalani hidup bersaudara, tetapi justru memperkaya hidup bersaudara. Paus juga menekankan pentingnya menghormati yang lebih tua, sementara yang lebih tua menunjukkan afeksi kepada yang muda. Dengan demikian, kenangan akan masa lalu didamaikan dengan janji akan masa depan. ${ }^{16}$

\section{Otonomi Biara ${ }^{17}$}

Paus Fransiskus menggarisbawahi bahwa tujuan otonomi adalah terciptanya stabilitas, kesatuan dan kontemplasi komunitas. Otonomi tidak berarti kemandirian atau isolasi. Para suster kontemplatif didorong untuk menghindari penyakit asyik dengan sendiri. ${ }^{18}$

Dei quaerere.

${ }^{14}$ Holy See Press Office, Summary of the Apostolic Constitution Vultum

${ }^{15} V D Q$, no. 24-27.

${ }^{16}$ Holy See Press Office, Summary of the Apostolic Constitution Vultum Dei quaerere.

$17 V D Q$, no. 28-29.

18 Holy See Press Office, Summary of the Apostolic Constitution Vultum Dei quaerere; Ricardo Benotti, "Vultum Dei quaerere", ...; José Rodriguez Carball, Prayer With No Bounds. 


\section{Federasi 19}

Paus mengingatkan pentingnya mengupayakan federasi sebagai struktur persekutuan di antara biara-biara yang memiliki karisma yang sama. Tujuan federasi adalah mempromosikan hidup kontemplatif dan menjamin pelaksanaan pendidikan awal dan pendidikan lanjut serta keterjaminan kebutuhan praktis lainnya. ${ }^{20}$

\section{Klausura $^{21}$}

Paus Fransiskus mengingatkan makna klausura sebagai tanda kesatuan eksklusif antara Gereja dengan Tuhan. Ada empat bentuk dan tingkatan klausura, yaitu klausura kepausan, klausura konstitusional dan klausura monastik. Perbedaan klausura mesti dilihat sebagai kekayaan dan bukan sebagai rintangan bagi kebersamaan.22

\section{Kerja $^{23}$}

Paus Fransiskus mengajak agar para suster kontemplatif, kiranya terinspirasi oleh semangat Ordo Benediktin orat et labora dalam melakukan pekerjaan. Paus berharap supaya para suster setia,bekerja tanpa jatuh dalam pola pikir dan kultur masa kini yang menekankan efisiensi. Paus mengawaskan supaya kerja tidak memadamkan semangat kontemplasi. Kerja mesti dimengerti sebagai kontribusi pada karya penciptaan dan pelayanan bagi umat manusia, solidaritas dengan orang miskin dan keseimbangan antara mencari yang Absolut dan komitmen pada pekerjaan sehari-hari. ${ }^{24}$

${ }^{19} V D Q$, no. 30.

${ }^{20}$ Holy See Press Office, Summary of the Apostolic Constitution Vultum Dei quaerere,... ; Ricardo Benotti, "Vultum Dei quaerere",...; José Rodriguez Carball, Prayer With No Bounds.

${ }^{21} V D Q$, no. 31.

${ }^{22}$ Holy See Press Office, Summary of the Apostolic Constitution Vultum Dei quaerere, ...; Scholastika Häring, Seeking the Face of God, ...

${ }^{23} V D Q$, no. 32.

${ }^{24}$ Holy See Press Office, Summary of the Apostolic Constitution Vultum Dei quaerere, ... 


\section{Keheningan $^{25}$}

Paus Fransiskus menegaskan bahwa keheningan adalah prasyarat yang memungkinkan kita menyambut kehadiran Allah. Tujuan keheningan adalah mendengarkan dan menerungan (ruminatio) Sabda Allah. Dengan mengosongkan diri, manusia dapat mendengarkan Allah dan jeritan manusia. Paus menyebut Bunda Maria yang tersuci sebagai contoh hidup dalam keheningan. Maria sanggup sanggup menerima Sang Sabda sebab dia adalah seorang wanita keheningan, yakni keheningan yang penuh dengan cinta. ${ }^{26}$

\section{Media Komunikasi27}

Menyadari perubahan dalam masyarakat dan maraknya budaya digital yang berdampak luas, baik dalam pola pikir pun cara berelasi. Kendati media komunikasi berguna untuk formasi, Paus menekankan perlunya kecerdasan yang bijaksana sehingga media komunikasi tidak menjadi kesempatan untuk memboroskan waktu atau melarikan diri dari tuntutan hidup persaudaraan, atau menjadi rintangan untuk menjalani hidup yang sepenuhnya diperuntukkan bagi kontemplasi. ${ }^{28}$

\section{Askese $^{29}$}

Askese dapat dirumuskan sebagai sikap sederhana, tidak melekat pada hal-hal material, penyerahan diri dalam ketaatan dan relasi yang transparan. Sebagai ciri hidup kontemplatif, askese sangat berkesan untuk umat Allah dan dunia yang mengalami globalisasi, tanpa akar dan sering terkoyak oleh konflik. Pemeluk hidup kontemplatif mampu tetap tinggal dekat dengan saudara yang lain kendati ada ketidakcocokan, ketegangan, konflik dan kelemahan. Paus menggarisbawahi, askese bukanlah pelarian dari dunia karena takut. Dengan tinggal di dunia, kendati bukan bagian dari dunia, religius

${ }^{25} V D Q$, no. 33.

${ }^{26}$ Holy See Press Office, Summary of the Apostolic Constitution Vultum Dei quaerere, ...

${ }^{27} V D Q$, no. 34.

${ }^{28}$ Holy See Press Office, Summary of the Apostolic Constitution Vultum Dei quaerere, ....

${ }^{29} V D Q$, no. 35. 
perempuan menjadi tanda kenabian yang tak kenal lelah, perantara bagi manusia di hadapan Allah, dan yang mendengarkan tangisan mereka yang menjadi korban keganasan budaya saling menyingkirkan. Dalam persekutuan yang mendalam dengan Gereja, para suster kontemplatif menjadi tangga di mana Allah turun untuk menjumpai manusia, dan manusia naik untuk bertemu dengan Allah. ${ }^{30}$

\section{Empat Belas Norma Yuridis ${ }^{31}$}

Konstitusi Apostolik Vultum Dei Quaerere ditutup dengan kesimpulan dan empat belas norma yuridis. Berikut ini dikemukakan beberapa nomor yang lebih penting:

Artikel 3 memuat ketentunan tentang pendidikan. Ditekankan perlunya menata program dan waktu serta menyediakan formator. Kerjasama antara biara untuk menyelengarakan pendidikan awal sangat dianjurkan. Para formator didorong untuk mengikuti kursus di luar biara. Juga ditegasan agar tidak mencari calon dari negara lain sematamata demi menjamin kelangsungan biara. ${ }^{32}$

Artikel 7 menegaskan supaya para suster yang dipanggil untuk tugas pelayanan sebagai pemimpin, di samping memperhatikan formasi, supaya mendorong terciptanya iklim penuh kegembiraan, saling percaya, kebebasan dan tanggung jawab demi kemajuan komunitas.

Artikel 8 memuat syarat otonomi yuridis suatu komunitas: kapasitas melakukan formasi dan kepemimpinan, partisipasi dalam kehidupan Gereja lokal, pemenuhan kebutuhan sendiri. Bila ketentuan di atas tidak memadai, maka Kongregasi untuk Institut Hidup Bakti akan akan mempelajari kemungkinan untuk menetapkan komisi ad hoc untuk merevitalisasi biara atau mengefektikan klausura. ${ }^{33}$

Artikel 9 menyebut bahwa awalnya, semua biara merupakan bagian dari federasi yang didirikan menurut kriteria geografis atau

${ }^{30}$ Holy See Press Office, Summary of the Apostolic Constitution Vultum Dei quaerere, ....

${ }^{31}$ Holy See Press Office, Summary of the Apostolic Constitution Vultum Dei quaerere, ....

32 Scholastika Häring, Seeking the Face of God, ....

33 Scholastika Häring, Seeking the Face of God, .... 
persamaan semangat dan tradisi. Jika suatu biara tidak bergabung dengan federasi lain, izin untuk berada di luar federasi merupakan urusan Tahta Suci. ${ }^{34}$

Artikel 14 menetapkan Kongregasi untuk Institusi Hidup Bakti mengeluarkan Instruksi mengenai penerapan kedua belas tema yang disebut di atas sambil memperhatikan karisma rumpun monastik. Instruksi tersebut mesti mendapat persetujuan dari Tahta Suci.

\section{Penutup}

Konstitusi Apostolik Vultum Dei Quaerere menyadarkan manusia akan pencarian dan kerinduannya terhadap Sang Absolut. Eksistensi hidup bakti dan lebih khusus lagi para suster kontemplatif ibarat suar yang memberi petunjuk menuju pelabuhan bagi para pelaut yang mengarungi samudera. Dengan terbitnya Konstitusi Apostolik ini para suster kontemplatif mendapat dasar legislasi baru. Paus Fransiskus mengajak pemeluk hidup kontemplatif supaya mencermati dua belas poin penting sebagai unsur esensial hidup kontemplatif, agar pencarian mereka akan wajah Allah dapat terwujud dan hidup mereka semakin berbuah.

$$
===0000===
$$

34 Scholastika Häring, Seeking the Face of God, .... 


\section{DAFTAR PUSTAKA}

Benotti, Ricardo., "Vultum Dei quaerere", Pope Francis on women's contemplative life: "the world needs you." Prudence with media communications and candidates' recruitment, dalam https://agensir.it/chiesa/2016/07/23/vultum-dei-quaerere-popefrancis-on-womens-contemplative-life-the-world-needs-youprudence-with-media-communications-and-candidatesrecruitment/

Carball, José Rodriguez., Prayer. With No Bounds, dalam http:// www.ewtn.com/library/PRIESTS/presvultum.htm

Francesco, Costituzione apostolica, 'Vultum Dei Quarerere, sulla vita contemplativa femminile' [PDF-Italian Langguage]

Francis, Apostolic Constituion 'Vultum Dei Quaerere on Women's Contemplative Life' [PDF-English Langguage]

Häring, Scholastika., Seeking the Face of God, a Commentary on the Apostolic Constitution Vultum Dei Quaerere: Contemplative Life in Religious Orders of Women, by Pope Francis, dalam http://www.aimintl.org/en/2015-05-29-13-29-49/ bulletin112/vultum-dei-quaerere

Holy See Press Office, Summary of the Apostolic Constitution Vultum Dei quaerere, dalam

https://press.vatican.va/content/salastampa/en/bollettino/pubb lico/2016/07/22/160722c.html

Vatican Radio, Apostolic Constitution, Vultum Dei quaerere (Seeking the Face of God), On Women's Contemplative Life, dalam https://www.cssr.news/2016/07/apostolic-constitution-vultumdei-quaerere-seeking-the-face-of-god-on-womens-contemplativelife/; 